\title{
REVISTA DE INVESTIGACIÓN RUMBO A LA MODERNIZACIÓN DIGITAL
}

\author{
Félix Dasio Ayala-Peralta ${ }^{1,2, a, b}$
}

La Revista Peruana de Investigación Materno Perinatal órgano oficial de difusión científica del Instituto Nacional Materno Perinatal (INMP) ha logrado ingresar a la modernización mediante el uso de la plataforma electrónica Open Journal System (OJS), la cual brindará una mayor visibilidad a la producción científica realizada en el INMP.

Al estar en el sistema del Open Journal System (OJS) la revista cuenta con un código internacional seriado en línea ISSN-L 2663-113X, quiere decir que la revista en su versión electrónica está visible a toda la comunidad científica, tanto nacional como internacional, cumpliendo de este modo con las normas establecidas para publicaciones científicas.

EI INMP viene publicando desde hace 8 años la Revista Peruana de Investigación Materno Perinatal en versión impresa con ISSN 2305-3887, la cual hasta la fecha han producido en su totalidad 121 artículos que ya se encuentran en línea y cada uno cuenta con Digital Object Identifier (DOI) que es un identificador único y permanente para las publicaciones en la red la cual garantiza el crédito académico de los investigadores que publican en nuestra revista.

En la actualidad, los artículos científicos producidos y publicados en vuestra revista del INMP tendrán mayor visibilidad porque cualquier investigador va a poder encontrarlos en la red, estos podrán citarlos como referencia en otros trabajos de investigación, dando inicio a la modernización en nuestras publicaciones como instituto de salud de nivel III-2 en el país.

A partir deL 2019, la edición de producción científica de vuestra revista en el INMP será más exigente y se realizará de manera trimestral, los artículos científicos serán inicialmente evaluados por revisores pares externos para luego ser aprobados por el Comité Editorial de la Revista, asegurando de este modo que los artículos sean de calidad y cuenten con los parámetros que las normas internacionales exigen.

Cabe mencionar que el INMP es el único instituto que ha logrado que una revista de investigación se encuentre indizada en LATINDEX y migrado al Open Journal System, el próximo paso es indizar la revista a plataformas como Scielo y otras. "Este es un proyecto sostenible, el camino está trazado para que la revista llegue a ser indizada a Scopus que es una base de datos bibliográficas del más alto nivel”. Vuestra revista está disponible en el link: http://investigacionmaternoperinatal.inmp.gob.pe/index.php/rpinmp

Editor General

\footnotetext{
Instituto Nacional Materno Perinatal.

2 Universidad Nacional Mayor de San Marcos. Departamento Académico de Ginecología y Obstetricia.

a Editor General de la Revista Peruana de Investigación Materno Perinatal

b Médico Gíneco Obstetra. Profesor Ordinario de la Facultad de Medicina de la Universidad Nacional Mayor de San Marcos. Lima- Perú. Citar como: Ayala-Peralta F. Revista de investigación rumbo a la modernización digital. Rev Peru Investig Matern Perinat. 2019;8(1):7. DOI: https://doi.org/10.33421/inmp.2019146
} 